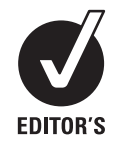

CHOICE

\title{
Malnutrition and nutrition support in patients with liver disease
}

\author{
John Saunders, ${ }^{1}$ Anna Brian, ${ }^{2}$ Mark Wright, ${ }^{2}$ Mike Stroud $^{3}$
}

'Department of Gastroenterology, Southampton University Hospital Trust, Southampton, UK ${ }^{2}$ Southampton University Hospital Trust, Southampton, UK ${ }^{3}$ Institute of Human Nutrition, University of Southampton, Southampton General Hospital, Southampton, UK

\section{Correspondence to} Dr I Saunders, Department of Gastroenterology, Southampton University Hospital Trust, F level, Centre Block, Tremona Road, Southampton S016 6YD, UK; john.saunders@doctors.org.uk

Accepted 17 February 2010
Liver disease, especially alcohol related, is increasingly common and is often accompanied by malnutrition as a result of reduced intake, absorption, processing and storage of nutrients. An increase or alteration in metabolic demands also occurs and some patients have high nutrient losses. Malnutrition in all forms of liver disease is associated with higher rates of mortality and morbidity but it is often under recognised and under treated despite the fact that appropriate treatment can improve outcomes. In this review, the causes, consequences and assessment of nutritional status in patients with liver disease are examined, and an approach to best treatment is proposed.

\section{Causes of malnutrition in liver patients} Malnutrition in chronic liver disease is multifactorial (see table 1).

\section{Impaired intake, digestion and absorption of nutrients}

All forms of acute or chronic liver problems may be accompanied by loss of appetite, and the presence of ascites can add striking early satiety. Low sodium diets can be very unpalatable and in alcoholic liver disease (ALD), patients often replace food calories with alcohol calories, or eat poorly due to oesophagitis, gastritis or pancreatitis. Food intake may also be poor with poverty or social isolation.

A degree of maldigestion is common in cirrhosis as a result of decreased bile salt solubilisation, and severe maldigestion is common in ALD with pancreatic damage. Malabsorption, with or without maldigestion, also occurs in alcoholics due to the toxic effects of alcohol on small intestinal ultrastructure and brush border enzymes. ${ }^{1}$ Many ALD patients therefore have rapid intestinal transit, increased mucosal permeability and impaired salt and water absorption. Absorptive problems are also seen with portal hypertension from any cause due to congestion of the intestinal mucosa. ${ }^{2}$

\section{Impaired nutrient storage}

The liver is the main store for many nutrients, particularly water soluble vitamins. Loss of storage capacity can therefore exacerbate micronutrient deficiencies caused by low or unbalanced dietary intakes. The best known example is that of thiamine deficiency in ALD although in this case there is actually a combination of poor storage, inadequate dietary intake, poor jejunal absorption and even alcohol promoted urinary loss. Nearly all ALD cirrhotics are therefore thiamine deficient and at high risk of Wernike Korsakoff syndrome.

\section{Impaired nutrient synthesis and altered nutrient demands}

Liver cirrhosis particularly affects protein metabolism with reductions in synthesis of transport proteins such as albumin. This is caused by a combination of decreased functional liver mass and alterations in amino acid (AA) demands. Reduced glycogen storage also increases AA needs for gluconeogenesis while ongoing inflammation alters the pattern of AA requirements, precipitating specific AA shortages. ${ }^{3}$ This problem is then made worse by a reduced capacity for transamination reactions which should allow the liver to generate AAs in short supply from those available. As a consequence of all of the above, patients with cirrhosis need considerably higher minimum daily protein intakes of around $60 \mathrm{~g}(1.2 \mathrm{~g} / \mathrm{kg} /$ day $)$ to maintain nitrogen balance rather than the $35 \mathrm{~g}(0.5 \mathrm{~g} / \mathrm{kg} /$ day $)$ needed by healthy individuals; so contrary to the popular misconception that all liver patients need low protein diets, high protein intakes are required if any improvement in lean tissue mass is to be achieved. ${ }^{4}$ Indeed, dietary protein retention remains efficient at much higher rates of provision than in normal individuals, with benefits seen at levels of up to $2.0 \mathrm{~g} / \mathrm{kg} / \mathrm{day}$, without adverse effects. ${ }^{5}$ Nevertheless, we believe 
Table 1 Causes of malnutrition in liver disease

\begin{tabular}{ll}
\hline Inadequate and/or poor quality oral & Anorexia of disease \\
intake & Abnormal taste \\
& Socioeconomic \\
& Calorie substitution from alcohol \\
& Dietary restriction (eg, low sodium) \\
& Poor dentition \\
& Pain on eating from oesophagitis, \\
& gastritis or pancreatitis \\
& Generalised weakness and \\
& immobility \\
& Ascites and early satiety \\
& Encephalopathy (including low \\
& grade) \\
& Reduction in bile salt pool \\
& Portal venous congestion \\
Maldigestion and malabsorption & Alcohol related small bowel damage \\
& Pancreatic insufficiency \\
& Bacterial overgrowth \\
Increased energy expenditure and & Many patients have a raised resting \\
altered substrate demands & energy expenditure \\
& Diarrhoea, bleeding and \\
paracentesis all cause nutrient & losses \\
\hline
\end{tabular}

that higher levels of protein provision should probably be avoided in acute liver disease or decompensated chronic liver disease.

Levels of overall energy demands in cirrhotic liver disease are subject to debate with resting energy expenditure (REE) studies showing conflicting results. The largest study to date in 473 patients showed that $34 \%$ of cirrhotics were hypermetabolic on indirect calorimetry but the causes of elevated REE were unclear and unrelated to clinical or biochemical assessments of impaired liver function. ${ }^{6}$ The increased energy expenditure may therefore reflect extrahepatic events in some liver disease patients such as the systemic inflammatory response. Overt or hidden infection also increases REE in cirrhotics and the presence of ascites per se seems to contribute since falls in REE are seen with paracentesis. ${ }^{7}$ Nevertheless, in one study hypermetabolism was still present in some patients 1 year after insertion of transjugular intrahepatic portosystemic shunts, even though ascites had resolved. ${ }^{8}$

\section{Abnormal nutrient losses}

Cirrhotic patients may lose both macro- and micronutrients from diarrhoea or gastrointestinal blood loss and renal losses of electrolytes are also higher than normal due to secondary hyperaldosteronism, sometimes exacerbated by diuretics. Renal losses of micronutrients, such as thiamine, are also increased, and paracentesis leads to large electrolyte and protein losses.

\section{The prevalence of malnutrition in liver patients}

Malnutrition is very common in chronic liver disease and is seen in about $20 \%$ of patients with compensated cirrhosis and in up to $60 \%$ of those with advanced disease. ${ }^{9}$ It is therefore more common than in cancer patients and is almost inevitable in patients awaiting liver transplantation. The aetiology of the cirrhosis does not affect the severity of overall malnourishment but does influence the susceptibility to particular deficiencies-for example, folate depletion effects up to $80 \%$ of ALD patients while cholestatic patients are more likely to develop fat soluble vitamin deficiencies.

\section{The consequences of malnutrition in liver patients}

Malnutrition appears to contribute to many of the complications of cirrhosis but it is difficult to assess the independent effects since progressive liver insufficiency is usually associated with both declining nutritional status and increased complications. Multivariate analysis has yielded conflicting results, especially as examination of multiple variables has meant that many studies are underpowered. For example, although Alberino and colleagues ${ }^{10}$ examining 212 hospitalised patients for 2 years found that malnutrition was an independent predictor of survival, Merli and colleagues ${ }^{11}$ in a larger study failed to show this association. It therefore remains unclear whether malnourished cirrhotics are more likely to die as a result of compromised nutritional status or whether patients who die are simply more likely to be malnourished. Whatever the cause of the relationship, however, poor nutritional status is associated with very poor outcomes.

Cirrhosis has a dramatic effect on body composition. Half of all patients are protein depleted and have reduced muscle function; this is significantly more prevalent in ALD and is higher in men (63\%) than in women (28\%). ${ }^{12}$ Møller and colleagues ${ }^{13}$ studied 55 patients with cirrhosis presenting with their first episode of variceal bleeding, using a Cox regression model to look at 55 different characteristics. Poor nutritional status emerged as one of five variables independently associated with a higher risk of rebleed or death $(\mathrm{p}<0.00005)$. Similarly, Kalaitzakis and colleagues ${ }^{14}$ studied 128 patients with encephalopathy and found significantly higher rates in malnourished compared with better nourished patients, especially if weight loss was recent, and although Sörös and colleagues ${ }^{15}$ failed to confirm this relationship in 223 patients with non-alcoholic cirrhosis, this may have been because assessment of recent weight loss was not included. Malnourished patients undergoing transplantation have higher short term postoperative complications, including increased infection rates, days in the intensive care unit, use of blood products and hospital stays. ${ }^{16}{ }^{17}$ Longer term graft survival also appears reduced.

\section{Identifying malnutrition in liver patients}

Although signs of malnutrition may be obvious in many liver patients, nutritional risk can be easily overlooked, and a high index of clinical suspicion is always appropriate. The National Institute for Health and Clinical Excellence (NICE) recommends that all patients should be screened for malnutrition at presentation but both screening and more detailed nutritional assessment are fraught with difficulties due to abnormalities in body weight and composition that are present in most liver patients. ${ }^{18}$ 
Liver disease often results in sodium and water retention, increasing apparent body weight. This may be obvious as in patients with ascites or oedema but may also be present in patients without clinically overt fluid retention. The changes in protein metabolism described above also lead to relative lean tissue wasting and most patients with severe liver disease have very abnormal body compositions. Defining these abnormalities accurately outside of research settings is difficult and there are no gold standards. However, the approaches in table 2 are often used.

\section{Treating malnutrition in liver patients-what to give}

Taking active steps to treat malnutrition in stable liver patients using either diet or some form of nutrition support is common sense but it is difficult to prove it is beneficial. Although liver patients must obviously eat or be fed in order to survive, obtaining ethical approval for randomised controlled trials (RCTs) of nutrition support versus continued relative starvation will always be problematic. Furthermore, even if ethical approval were granted, recruiting suitably 'informed' patients would be virtually impossible. As a result, studies of nutrition in liver patients have tended to be small, comparing standard feeding with provision of some supplementary intake. This leads to reduced effect size and consequent difficulty in evaluating the

Table 2 Nutritional assessment techniques in patients with liver cirrhosis

Assessment technique Screening Tool

Subjective Global Assessment and the Prognostic Nutritional Index

The Royal Free Hospital Global Assessment

Mid upper arm muscle circumference (MAMC)

Hand grip strength

Bioelectrical impedance analysis

\section{Considerations}

Although not designed for cirrhotic patients can make allowances for ascites and oedema if the problem is recognised but this may not happen in practice ${ }^{37}$

Both have been used to assess nutritional status but tend to underestimate prevalence ${ }^{38-40}$

This is reproducible and valid against measures of body composition. It can also help predict survival ${ }^{41}$

This assesses lean tissue status and is little affected by salt and water retention. It is derived from mid upper arm circumference (MAC) and triceps skinfold thickness (TSF) as follows:

MAMC $=$ MAC $-(3.14 \times$ TSF $)$

\section{Coupled with measures of arm} circumference, has been shown to have a sensitivity of $94 \%$ and negative predictive value of $97 \%$ in identifying depleted body cell mass in cirrhotics. ${ }^{38}$ Grip strength is also the best modality for predicting major complications at 1 year. ${ }^{39}$ Nevertheless, it is reliant on patient volition and rarely used in clinical practice

Recommended as a reliable bedside tool by the European Society for Clinical Nutrition and Metabolism but has considerable limitations in liver disease patients with their abnormal salt and water distribution. 4243 true importance of nutritional care. Nevertheless, individual trials of nutrition in stable liver patients do indicate treatment benefit (see table 3).

Treating malnutrition, let alone undertaking trials, is even more difficult in acute-severe or decompensated-chronic liver disease with potential sepsis, renal impairment, ascites, sodium restrictions and encephalopathy. The optimal route for providing nutritional support in such patients tends to change with time, with enteral tube or even parenteral nutrition needed early in the course of illness, moving to oral supplements and/or meals as things improve. Furthermore, optimal target levels for feeding should also vary with disease progress, and for reasons outlined below, we believe that initial low levels may be better when patients are decompensated or acutely ill, followed by a move to maintenance levels as they begin to recover and high levels once the patients are stable and able to regain lean body mass. These ideas, however, are not accepted by all authorities and some guidelines recommend target levels of early feeding in sick patients that we think are too high.

\section{Energy and protein intakes}

In malnourished cirrhotic patients, most guidelines suggest an intake of $35-40 \mathrm{kcal} / \mathrm{kg} /$ day with a protein intake of at least $1.2-1.5 \mathrm{~g} / \mathrm{kg} / \mathrm{day} .{ }^{19}$ This seems sensible as it will maximise positive nitrogen balance and accrual of lean tissues, and so hopefully improve overall health status. However, feeding acutely ill patients with either acute disease or acute-on-chronic problems at such high levels may not be helpful for even though energy demands are raised and some evidence suggests that high nitrogen provision achieves best nitrogen balance, high levels of feeding do not equate to better patient outcomes and logic suggests commencement at lower levels. ${ }^{20}$ The thinking behind this apparent paradox is that providing nutrients that cannot be fully utilised by sick patients could potentially add problems of hyperglycaemia, lipaemia and refeeding to ongoing metabolic stress, especially if pre-existing malnutrition, vitamin and electrolyte deficiencies or liver dysfunction limit a patient's overall metabolic capacity to handle exogenous substrates. Furthermore, as the systemic inflammatory response and immune expansion lead to unusual AA demands, higher levels of protein provision will cause a surfeit of unwanted AAs that demand metabolic disposal. ${ }^{3}$ We therefore recommend following the current NICE guidance that feeding in all seriously ill patients is introduced at rates meeting about $50 \%$ of maintenance energy and protein requirements, while meeting full electrolyte, micronutrient and fluid needs. ${ }^{18}$ We estimate maintenance energy requirements using a value of $120 \%$ of resting metabolic rate (calculated using, for example, Schofield's equation) and maintenance levels of protein as approximately $0.7 \mathrm{~g}$ protein $/ \mathrm{kg} /$ day. ${ }^{21}$ Feeding levels can then be built up after $48 \mathrm{~h}$ to meet full maintenance needs, with later 
Table 3 Trials demonstrating benefit of nutritional intervention

\begin{tabular}{|c|c|c|c|}
\hline $\begin{array}{l}\text { Type of } \\
\text { nutritional } \\
\text { support }\end{array}$ & Authors & Intervention & Main outcome measure \\
\hline \multirow[t]{4}{*}{ Enteral } & Cabre et $a /^{34}$ & $\begin{array}{l}\text { RCT comparing tube feeding with standard diet } \\
\text { ( } 2115 \mathrm{kcal} / \text { day) in patients with severe malnutrition }\end{array}$ & Significant reduction in mortality as inpatient ( $12 \%$ vs $47 \%$ ) \\
\hline & Hirsch et $a^{/ 33}$ & $\begin{array}{l}1000 \mathrm{kcal} \text { ( } 34 \mathrm{~g} \text { protein) daily supplement } \\
\text { compared with placebo }\end{array}$ & Reduction in hospitalisation \\
\hline & Bunout et $a l^{44}$ & $\begin{array}{l}\text { Intake of } 50 \mathrm{kcal} / \mathrm{kg} / \text { day and } 1.5 \mathrm{~g} \text { protein } / \mathrm{kg} / \text { day } \\
\text { compared with standard diet }\end{array}$ & Non-significant reduction in mortality \\
\hline & Kearns et a $\left.\right|^{35}$ & Intake of $167 \mathrm{kcal} / \mathrm{kg} /$ day and $1.5 \mathrm{~g}$ protein/kg/day & $\begin{array}{l}\text { Improvement of surrogate markers of liver disease, no } \\
\text { significant reductions in primary end points }\end{array}$ \\
\hline Parenteral & Wicks et a $/^{45}$ & $\begin{array}{l}\text { Comparison between enteral and parenteral feeding } \\
\text { immediately post-OLT }\end{array}$ & No difference between two groups \\
\hline \multirow[t]{2}{*}{$\begin{array}{l}\text { Branch chain } \\
\text { amino acid }\end{array}$} & Muto et a ${ }^{25}$ & BCAA (12 g/day for 2 years) oral supplement RCT & $\begin{array}{l}\text { Significant reduction in primary outcome (mortality, HCC, } \\
\text { variceal bleed and progression of disease) }\end{array}$ \\
\hline & Marchesini et a/24 & BCAA oral supplement RCT & $\begin{array}{l}\text { Significant reduction in hospital admissions and surrogate } \\
\text { markers of nutrition }\end{array}$ \\
\hline
\end{tabular}

BCAA, branched chain amino acid; HCC, hepatocellular carcinoma; OLT, orthotopic liver transplantation; RCT, randomised controlled trial.

further increases to replenishment feeding at or above the levels suggested for stable cirrhotic patients. ${ }^{19}$ Even lower commencement feeding rates and more cautious rates of increase may be warranted in patients at high risk of refeeding problems. ${ }^{18}$

Feeding patients with encephalopathy raises further questions. For many years, conventional wisdom was to provide low protein diets to limit levels of circulating nitrogenous metabolic products that may contribute to the neurotoxicity. However, most studies actually suggest that low protein diets have little or no effect on encephalopathy and may actually cause harm through worsening nutritional status. ${ }^{22}$ We therefore recommend that patients with encephalopathy are offered the same levels of protein as other liver patients-that is, relatively high levels if otherwise stable but lower initial levels if very unwell.

Treatment with supplementary branched chain amino acids (BCAAs) was also thought to benefit patients with encephalopathy but fell out of common practice after a Cochrane meta-analysis in 2003 showed no convincing benefit. ${ }^{23}$ More recently, however, the possibility that BCAAs are of benefit in relation to other aspects of liver disease has been raised, with an Italian multicentre RCT of 174 patients with advanced cirrhosis performed over 1 year showing lower rates of hospital admission, reduced Child-Pugh scores and improved quality of life. ${ }^{24}$ Furthermore, a larger prospective multicentre RCT in advanced cirrhosis also demonstrated benefit from BCAA supplementation over a 2 year period in terms of death, development of liver cancer, variceal bleeding and progression of liver failure. ${ }^{25}$ However, further work is needed to confirm these potentially important findings.

\section{Non-protein energy}

There is very little published evidence on optimal ratios of glucose to lipid energy that should be given to malnourished patients with liver disease. The current European Society for Clinical Nutrition and Metabolism guidelines suggest that glucose should provide $50-60 \%$ of non-protein energy and lipid about $40-50 \%{ }^{26}$ However, the recommendation is based on two small studies both aimed at treating hepatic encephalopathy with BCAAs in hospitalised patients. ${ }^{27}$ ${ }^{28}$ There is some evidence which supports the use of newer fat emulsions that have a lower content of $n-6$ unsaturated fatty acids, which potentially renders them less suppressive to leucocyte and immune function. ${ }^{29}$

\section{Electrolytes and minerals}

Most patients with severe acute or chronic liver disease have derangements in electrolyte and mineral balance that need to be monitored closely. Hyperaldosteronism, triggered by vasodilatation and enhanced by defective hepatic aldosterone metabolism, is perhaps the most common problem, and can lead to very severe sodium and water retention. However, the practice of imposing very tight restrictions on sodium provision from diet or other routes is no longer followed by most units as restrictions of greater than about $90 \mathrm{mmol} /$ day make food unpalatable and hence reduce overall nutrient intakes. ${ }^{30}$

Renal failure, secondary to hepatorenal syndrome, is also common in liver patients and may force severe restrictions on potassium, calcium and phosphate intakes. Conversely, refeeding syndrome is a potential problem in some liver patients who then need very generous potassium, phosphate and magnesium provision. Following the NICE refeeding guidance, feeding regimens from as little as $10 \mathrm{kcal} / \mathrm{kg} / \mathrm{day}$, building up to maintenance levels over 4-7 days, with careful monitoring and replacement of electrolytes, may be needed. ${ }^{18}$

\section{Micronutrients}

Provision of adequate micronutrients is as important as provision of macronutrients and, indeed, if not undertaken may limit metabolic utilisation of protein, 
carbohydrate and fat. Alcoholic liver patients are particularly prone to deficiencies in folate, vitamin $\mathrm{C}$ and thiamine while patients with cirrhosis of any origin, especially those with cholestatic liver disease, are at particular risk of developing fat soluble vitamin deficiencies. Vitamin D deficiency occurs frequently as a result of both inadequate diet and malabsorption and results in osteoporosis which is evident in 40\% of patients undergoing transplantation. Vitamin A deficiency and night blindness are also documented in cirrhosis, and some patients with ALD develop frank zinc deficiency with orogenital skin rashes.

Measurement of micronutrients in the acute setting is usually unrewarding due to the effects of the acute phase response on circulating levels and the time involved in getting results back. We therefore recommend that all patients are given balanced multivitamin and trace element preparations with specific

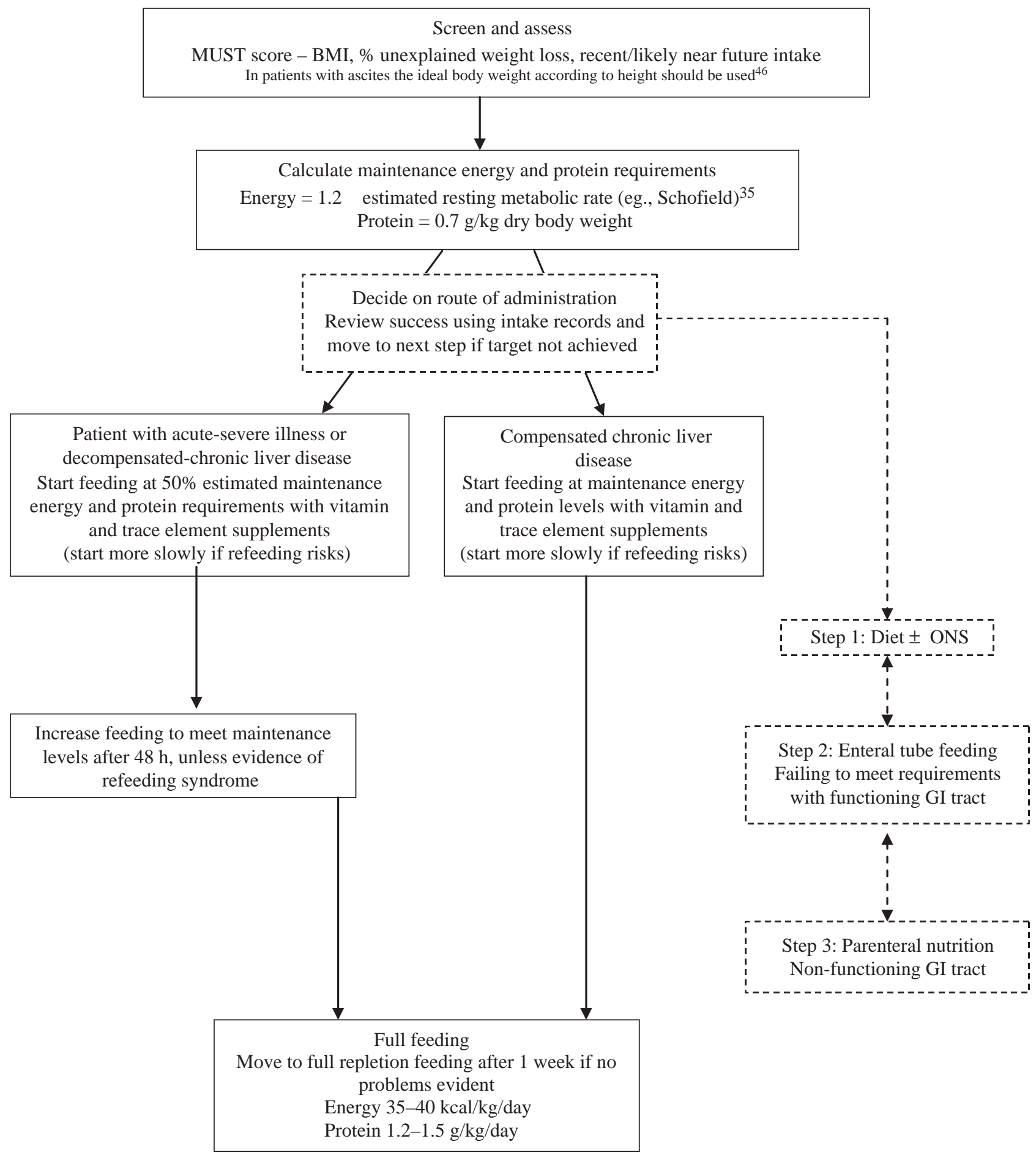

Figure 1 Practical approaches to the nutritional management of liver patients. BMI, body mass index. ONS, oral nutritional supplements. 
supplementation of thiamine and folate in ALD patients. Pabrinex (Link Pharmaceuticals Ltd, Horsham, UK) is useful as an intravenous, thiamine containing preparation but is often used as a generic 'vitamin fix' which is not entirely appropriate as it does not contain folic acid, which is one of the commonest deficiencies seen in liver patients. It also contains no fat soluble vitamins or trace elements.

\section{Treating malnutrition in liver patients-how to provide support}

Figure 1 illustrates a sequential approach to both the method of providing nutritional support and the level of feeding based on our own clinical practice.

\section{Dietary counselling, special menus and oral nutritional supplements}

In practice, achieving significant changes in oral intake through dietary counselling and special menus alone can be difficult. Consuming small meals should be encouraged as many patients complain of early satiety, particularly those with ascites, and the 'little and often' approach, especially with a late evening carbohydrate snack, has also been shown to improve nitrogen balance in cirrhotic patients, probably by limiting the demands on AAs for gluconeogenesis. ${ }^{31}$

Oral nutritional supplements are not necessarily better than adequate dietary counselling in improving clinical outcome in malnourished liver patients but they do offer immediate simple means of increasing oral intake. ${ }^{32}$ Higher protein formulations can be helpful in meeting high protein requirements, and in a study by Hirsch and colleagues, ${ }^{33}$ of 51 outpatients with decompensated ALD treated with oral nutritional supplements for 1 year, improvements in nutritional parameters and a reduced frequency of hospitalisation were seen.

\section{Enteral tube feeding}

Enteral tube feeding (ETF) is frequently needed in hospitalised patients because sick patients usually fail to meet even modest nutritional targets. Cabre et al in an RCT demonstrated a reduction in mortality $(47 \%$ vs 12\%) in hospitalised (malnourished) cirrhotic patients treated with ETF and several other RCTs have shown that tube feeding can reduce markers of disease severity and possibly reduce mortality. ${ }^{33-35}$

Although there is often concern that the passage of a nasogastric tube may lead to rupture and bleeding from oesophageal varices, especially after an acute bleed, several studies suggest that this is not the case. ${ }^{34-36}$ Mere suspicion of oesophageal varices should not therefore delay ETF although acute bleeding should be controlled before the passage of the tube.

\section{Parenteral nutrition}

Parenteral nutrition should be reserved for patients who are unable to receive or tolerate oral or enteral feeding. In practice, parenteral nutrition is often unworkable because patients pull out central venous catheters as a result of encephalopathy, and it is associated with high rates of central venous catheter infection, which is particularly concerning in cirrhotic patients with impaired immunity. Parenteral nutrition itself can also cause a number of problems with the liver, both in the short and longer term that are beyond the scope of this review, which impair liver function and therefore worsen pre-existing liver disease in cirrhotic patients.

\section{Conclusions}

Malnutrition is very common in liver disease and gets worse with the severity of the underlying liver problem. Poor nutritional status is associated with a worse prognosis with respect to mortality, encephalopathy, variceal bleeding and infection. It is generally easy to recognise but often overlooked. Simple screening tools can highlight risk, and other measurements are useful as prognostic indicators. It is important that nutrition is provided in appropriate amounts at appropriate stages of the clinical course, especially in patients who are metabolically unstable with poorly functioning livers. There is evidence that careful nutritional support is beneficial, and by implementing a targeted practical approach in clinical settings, improvements in patient outcomes can be seen.

Competing interests None.

Provenance and peer review Commissioned; not externally peer reviewed.

\section{References}

1. Bhonchal S, Nain CK, Prasad KK, et al. Functional and morphological alterations in small intestine mucosa of chronic alcoholics. J Gastroenterol Hepatol 2008;23:e43-8.

2. Taylor RM, Bjarnason I, Cheeseman P, et al. Intestinal permeability and absorptive capacity in children with portal hypertension. Scand J Gastroenterol 2002;37:807-11.

3. Reeds PJ, Fjeld CR, Jahoor F. Do the differences between the amino acid compositions of acute-phase and muscle proteins have a bearing on nitrogen loss in traumatic states? J Nutr 1994;124:906-10.

4. Swart GR, van den Berg JW, van Vuure JK, et al. Minimum protein requirements in liver cirrhosis determined by nitrogen balance measurements at three levels of protein intake. Clin Nutr 1989;8:329-36.

5. Nielsen K, Kondrup J, Martinsen L, et al. Long-term oral refeeding of patients with cirrhosis of the liver. Br J Nutr 1995;74:557-67.

6. Müller MJ, Böttcher J, Selberg O, et al. Hypermetabolism in clinically stable patients with liver cirrhosis. Am J Clin Nutr 1999;69:1194-201.

7. Dolz C, Raurich JM, Ibáñez J, et al. Ascites increases the resting energy expenditure in liver cirrhosis. Gastroenterology 1991;100:738-44.

8. Plauth M, Schütz T, Buckendahl DP, et al. Weight gain after transjugular intrahepatic portosystemic shunt is associated with improvement in body composition in malnourished patients with cirrhosis and hypermetabolism. J Hepatol 2004;40: 228-33.

9. Nutritional status in cirrhosis. Italian Multicentre Cooperative Project on Nutrition in Liver Cirrhosis. J Hepatol 1994;21:317-25. 
10. Alberino F, Gatta A, Amodio P, et al. Nutrition and survival in patients with liver cirrhosis. Nutrition 2001;17:445-50.

11. Merli M, Riggio O, Dally L. Does malnutrition affect survival in cirrhosis? PINC (Policentrica Italiana Nutrizione Cirrosi). Hepatology 1996;23:1041-6.

12. Peng S, Plank LD, McCall JL, et al. Body composition, muscle function, and energy expenditure in patients with liver cirrhosis: a comprehensive study. Am J Clin Nutr 2007;85:1257-66.

13. Møller S, Bendtsen F, Christensen E, et al. Prognostic variables in patients with cirrhosis and oesophageal varices without prior bleeding. J Hepatol 1994;21:940-6.

14. Kalaitzakis E, Olsson R, Henfridsson P, et al. Malnutrition and diabetes mellitus are related to hepatic encephalopathy in patients with liver cirrhosis. Liver Int 2007;27:1194-201.

15. Sörös $\mathbf{P}$, Böttcher J, Weissenborn K, et al. Malnutrition and hypermetabolism are not risk factors for the presence of hepatic encephalopathy: a cross-sectional study. J Gastroenterol Hepatol 2008;23:606-10.

16. Harrison J, McKiernan J, Neuberger JM. A prospective study on the effect of recipient nutritional status on outcome in liver transplantation. Transpl Int 1997;10:369-74.

17. Stephenson GR, Moretti EW, El-Moalem H, et al. Malnutrition in liver transplant patients: preoperative subjective global assessment is predictive of outcome after liver transplantation. Transplantation 2001;72:666-70.

18. National Institute for Health and Clinical Excellence. Nutrition Support in Adults. London: NICE, 2006.

19. Plauth M, Merli M, Kondrup J, et al. ESPEN guidelines for nutrition in liver disease and transplantation. Clin Nutr 1997;16:43-55.

20. Stroud M. Protein and the critically ill; do we know what to give? Proc Nutr Soc 2007;66:378-83.

21. Schofield WN. Predicting basal metabolic rate, new standards and review of previous work. Hum Nutr Clin Nutr 1985;39(Suppl 1):5-41.

22. Córdoba J, López-Hellín J, Planas M, et al. Normal protein diet for episodic hepatic encephalopathy: results of a randomized study. J Hepatol 2004;41:38-43.

23. Als-Nielsen B, Koretz RL, Kjaergard LL, et al. Branched-chain amino acids for hepatic encephalopathy. Cochrane Database Syst Rev 2003;2:CD001939.

24. Marchesini G, Bianchi G, Merli M, et al. Nutritional supplementation with branched-chain amino acids in advanced cirrhosis: a double-blind, randomized trial. Gastroenterology 2003;124:1792-801.

25. Muto Y, Sato S, Watanabe A, et al. Effects of oral branchedchain amino acid granules on event-free survival in patients with liver cirrhosis. Clin Gastroenterol Hepatol 2005;3: 705-13.

26. Plauth M, Cabré E, Campillo B, et al. ESPEN Guidelines on Parenteral Nutrition: hepatology. Clin Nutr 2009;28:436-44.

27. Michel H, Bories P, Aubin JP, et al. Treatment of acute hepatic encephalopathy in cirrhotics with a branched-chain amino acids enriched versus a conventional amino acids mixture. A controlled study of 70 patients. Liver 1985;5:282-9.

28. Wahren J, Denis J, Desurmont P, et al. Is intravenous administration of branched chain amino acids effective in the treatment of hepatic encephalopathy? A multicenter study. Hepatology 1983;3:475-80.

29. Mayer K, Meyer S, Reinholz-Muhly M, et al. Short-time infusion of fish oil-based lipid emulsions, approved for parenteral nutrition, reduces monocyte proinflammatory cytokine generation and adhesive interaction with endothelium in humans. J Immunol 2003;171:4837-43.

30. Runyon BA. Management of adult patients with ascites due to cirrhosis: an update. Hepatology 2009;49:2087-107.

31. Swart GR, Zillikens MC, van Vuure JK, et al. Effect of a late evening meal on nitrogen balance in patients with cirrhosis of the liver. BMJ 1989;299:1202-3.

32. Le Cornu KA, McKiernan FJ, Kapadia SA, et al. A prospective randomized study of preoperative nutritional supplementation in patients awaiting elective orthotopic liver transplantation. Transplantation 2000;69:1364-9.

33. Hirsch S, Bunout D, de la Maza P, et al. Controlled trial on nutrition supplementation in outpatients with symptomatic alcoholic cirrhosis. JPEN J Parenter Enteral Nutr 1993;17: 119-24.

34. Cabre E, Gonzalez-Huix F, Abad-Lacruz A, et al. Effect of total enteral nutrition on the short-term outcome of severely malnourished cirrhotics. A randomized controlled trial. Gastroenterology 1990;98:715-20.

35. Kearns PJ, Young H, Garcia G, et al. Accelerated improvement of alcoholic liver disease with enteral nutrition. Gastroenterology 1992;102:200-5.

36. de Lédinghen V, Beau P, Mannant PR, et al. Early feeding or enteral nutrition in patients with cirrhosis after bleeding from esophageal varices? A randomized controlled study. Dig Dis Sci 1997;42:536-41.

37. Elia M (chairman and editor). The 'MUST' report: nutritional screening for adults: a multidisciplinary responsibility. Development and Use of the 'Malnutrition Universal Screening Tool' (MUST) for Adults. A report by the Manutrition Advisory Group of the British Association for Parenteral and Enteral Nutrition, 2003.

38. Figueiredo FA, Dickson ER, Pasha TM, et al. Utility of standard nutritional parameters in detecting body cell mass depletion in patients with end-stage liver disease. Liver Transpl 2000;6:575-81.

39. Alvares-da-silva MR, Reverbel da Silveira T. Comparison between handgrip strength, subjective global assessment and prognostic nutritional index in assessing malnutrition and predicting clinical outcome in cirrhotic outpatients. Nutrition 2005;21:113-17.

40. Figueiredo FA, Perez RM, Freitas MM, et al. Comparison of three methods of nutritional assessment in liver cirrhosis: subjective global assessment, traditional nutritional parameters, and body composition analysis. J Gastroenterol 2006;41: 476-82.

41. Morgan MY, Madden AM, Soulsby CT, et al. Derivation and validation of a new global method for assessing nutritional status in patients with cirrhosis. Hepatology 2006;44:823-35.

42. Plauth M, Cabré E, Riggio O, et al. ESPEN Guidelines on Enteral Nutrition: liver disease. Clin Nutr 2006;25:285-94.

43. Pirlich M, Schütz T, Spachos T, et al. Bioelectrical impedance analysis is a useful bedside technique to assess malnutrition in cirrhotic patients with and without ascites. Hepatology 2000;32:1208-15.

44. Bunout D, Aicardi V, Hirsch S, et al. Nutritional support in hospitalized patients with alcoholic liver disease. Eur J Clin Nutr 1989;43:615-21.

45. Wicks C, Somasundaram S, Bjarnason I, et al. Comparison of enteral feeding and total parenteral nutrition after liver transplantation. Lancet 1994;344:837-40.

46. Mendenhall C. Protein-calorie malnutrition in alcoholic liver disease. In: Watson R, Watzl B, eds. Nutrition and alcohol. Boca Raton, Florida, USA: CRC press, 1992:363-84. 